\title{
UTILIZANDO O GOOGLE CLASSROOM COMO FERRAMENTA EDUCACIONAL - PERCEPÇÕES E POTENCIAIS
}

PARÁ DE MINAS/MG JUNHO/2018

\author{
Rafael Henriques Nogueira Diniz - FAPAM - rafael.diniz@fapam.edu.br \\ Juliana Cristina Fraleon de Almeida - FAPAM - juliana.almeida@fapam.edu.br \\ Bruna Fernanda Lopes Rodrigues - FAPAM - bruna.rodrigues@fapam.edu.br \\ Miriam Maria Roberto Marmol - FAPAM - miriam.marmol@fapam.edu.br
}

Tipo: Investigação Científica (IC)

Natureza: Relatório Final de Pesquisa

Categoria: Métodos e Tecnologias

Setor Educacional: EDUCAÇÃO SUPERIOR

\begin{abstract}
RESUMO
O presente artigo apresenta uma investigação sobre a utilização da ferramenta Google Classroom em sala de aula. A experiência ocorreu durante uma disciplina do curso de Gestão da Tecnologia da Informação da Faculdade de Pará de Minas - FAPAM, modalidade presencial. Foi utilizado a ferramenta durante o primeiro semestre letivo de 2018. A seguir apresentamos considerações sobre seu a utilização, desafios e pontos positivos e negativos e potenciais de seu uso tanto na área educacional.
\end{abstract}

Palavras-chave: Google Classroom; Tecnologias; Ferramentas para a educação.

\section{AGRADECIMENTOS}

AGRADECEMOS A FACULDADE DE PARÁ DE MINAS - FAPAM PELO APOIO E INCENTIVO A PESQUISA. AOS ALUNOS DO CURSO DE GTI PELA DISPONIBILIDADE EM RESPONDER A PESQUISA. 


\title{
Introdução
}

As Tecnologias da Informação e Educação (TIC) estão cada vez mais presentes em nosso cotidiano. Na educação, ela se apresenta como um valioso recurso no auxílio ao processo de ensino e aprendizagem. Porém, Prandini (2009) alerta que a tecnologia permite um grande acesso às informações, porém por si só não promove condições de aprendizagens para aqueles que tem acesso a elas. Nessa conjuntura, Araújo (2016) afirma os profissionais de educação possuem um papel muito importante neste cenário, onde para trabalharem respectivas tecnologias, há de se ter o domínio da técnica e o planejamento necessário e minucioso.

Valente (1999) afirma que:

\begin{abstract}
O esforço para criar ambientes de aprendizagens baseados no computador para as diferentes populações, mostrou que, quando é dada a oportunidade para essas pessoas compreenderem o que fazem, elas experimentam o sentimento de empowerment - a sensação de que são capazes de produzir algo considerado impossível. Além disso, conseguir um produto que eles não só construíram, mas compreenderam como foi realizado. Eles podem falar sobre o que fizeram e mostrar esse produto para outras pessoas. É um produto da mente deles, e isso acaba proporcionando uma confiança nas próprias capacidades, dão aos estudantes $O$ incentivo para continuar melhorando suas capacidades mentais e depurando suas ações e ideias. (VALENTE, 1999, p.82).
\end{abstract}

Para Araújo (2016), as utilizações de tecnologias online permitem um potencial de ensino inovador. A autora ressalta que promove a facilidade do trabalho de professores e para aprendizagem dos estudantes. A possibilidade de se utilizar recursos como imagens, vídeos, sons, textos e animações, permitem momentos lúdicos de aprendizagem. Além disso, os estudantes se mostram ávidos por utilizarem tecnologias como forma de seu aprendizado. As utilizações dos recursos tecnológicos na educação permitem enriquecer e criar um ambiente dinâmico para aprendizagem. São inúmeras ferramentas de auxílio ao gerenciamento do ensino, tais como: Moodle (Modular ObjectOriented Dynamic Learning Environment), Canvas, Blackboard, dentre outras. Existem as redes sociais que possuem finalidades distintas, porém que podem ser utilizadas para educação, tais como: Facebook, Instagram e Whatsapp. Estas ferramentas tendem a já possuir a afinidade dos estudantes, devido a grande maioria já pertencer a este espaço. Finardi e Pimentel (2013) afirmam que o Facebook é uma ferramenta que pode ajudar na interação aluno-professor. Porém nestes ambientes, o professor precisa planejar e estar presente no ambiente como moderador e fomentador de discussões, de forma com que o conteúdo não fique perdido ou abandonado.

No ano de 2014 a gigante empresa de tecnologia Google aposta em uma ferramenta para a área educacional denominada GoogleClassroom. Sua proposta de permitir que 
instituições de ensino utilizem uma ferramenta de qualidade e gratuita, bastando a utilização de um simples email se torna atrativa. A ferramenta facilita a comunicação entre professores e estudantes, promove o interesse dos mesmos na participação dos conteúdos e cria uma extensão da sala de aula em um ambiente virtual.

Nesta perspectiva, o presente trabalho tem como objetivo apresentar os resultados de uma pesquisa com alunos do curso de Gestão da Tecnologia da Informação da FAPAM sobre as percepções dos mesmos sobre os potenciais e qualidade da ferramenta Google Classroom.

\title{
Desenvolvimento
}

Segundo Pressman (2009), os softwares são programas que tem como objetivo realizar atividades e objetivos específicos para os usuários.

Para Kensky (2006):

\begin{abstract}
Não há dúvida que as novas tecnologias de comunicação e informação trouxeram mudanças consideráveis e positivas para a educação. Vídeos, programas educativos na televisão e no computador, sites educacionais, softwares diferenciados transformam a realidade da aula tradicional, dinamizam o espaço de ensino e aprendizagem, onde, anteriormente predominava a lousa, o giz, o livro e a voz do professor. (Kensky, 2006. P. 46).
\end{abstract}

Logo, com a adoção de tecnologias da informação de forma contextualizada, o ambiente educacional passa a tornar-se atrativo para o estudante. Ele vê oportunidades de estudo e crescimento.

\section{Sobre o Google Classroom}

O Google Classroom ou Google Sala de Aula é um software para ambientes educacionais. Faz parte da suíte de aplicativos Google for Education, desenvolvidos para o fomento e utilização na educação, juntamente a ferramenta de email (GMAIL), armazenamento de arquivos (DRIVE) e editores de textos, planilhas e apresentações (DOCS).

Segundo Araújo (2016) é possível no Google Classroom criar turmas, partilhar documentos, propor tarefas e promover discussões. De forma simples e intuitiva, o docente consegue organizar suas aulas em formato de tópicos, tendo a possibilidade de compartilhar documentos, áudios, vídeos, links e uma infinidade de possibilidades. Além disso, é possível criar notas de avisos, atividades que permitem a correção, nota e feedback. O ambiente é limpo, sem informações excessivas, tampouco complexo seu 
acesso, bastando apenas o acesso via email, que geralmente o aluno já possui ou pode criar dentro da plataforma Google. Sua interface é semelhante a uma rede social, onde de forma lúdica o estudante consegue visualizar todo o conteúdo de forma ágil. Há ainda a possibilidade de acesso via smartphone através do site e do aplicativo disponibilizado para Android e IOS.

A cada tópico criado ou conteúdo enviado à plataforma todos os membros do grupo recebem um alerta por email, facilitando o contato do professor com os alunos. Os arquivos e conteúdos enviados são armazenados na tecnologia (DRIVE) disponível pelo Google, de forma que o docente não se preocupa inicialmente com a armazenagem dos arquivos. Como mecanismo de inserção e cadastro de turmas, tudo ocorre intuitivamente, ao tempo que o docente pode criar a sala de aula e convidar os alunos participantes por email ou enviando uma chave de acesso correspondente ao endereço da sala.

Como pré-requisito para utilização da plataforma, o docente deverá possuir uma conta na Google para proceder o início da turma.

A seguir apresentamos algumas vantagens sobre a utilização do Google Classroom:

- Configuração fácil;

- Não faz uso dos conteúdos e dados dos alunos;

- Não contém anúncios ou propagandas;

- Permite ambientes de comentários;

- Facilita a organização dos materiais.

- Dispensa de papel;

- Estabelecimento de prazos e horários;

Como desvantagens da ferramenta é a necessidade de internet como pré-requisito ao acesso dos arquivos. Neste caso, antes da implantação e utilização da ferramenta, devese verificar se todos os alunos conseguem de alguma forma ter acesso a pontos de conexão de internet. É um fator que deve ser planejado para não se tornar excludente.

\section{Metodologia}

A pesquisa desenvolvida foi baseada no método qualitativo, que segundo Marconi e Lakatos (2007), é uma forma de pesquisa que se identifica por dados analisados de acordo com o conteúdo social e as amostras são reduzidas. Os autores ressaltam que a pesquisa qualitativa se preocupa em "analisar e interpretar aspectos mais profundos, 
descrevendo a complexidade do comportamento humano, fornecendo uma análise mais detalhada sobre as investigações, hábitos, atitudes, tendências de comportamento" (MARCONI E LAKATOS, 2007, p. 269).

Para Gil (2008), esse tipo de pesquisa tem como objetivo principal o aprimoramento de ideias ou a descoberta de intuições.

Em relação aos procedimentos técnicos para a coleta de dados, a pesquisa utilizou-se um questionário online enviado para os estudantes do primeiro e quinto períodos do curso de Gestão da Tecnologia da Informação da FAPAM modalidade presencial. Ao todo, participaram doze alunos, sendo sete do primeiro período e cinco do quinto período. O objetivo do questionário era analisar a percepção dos alunos quanto a utilização da ferramenta Google Classroom.

\section{Análise dos Dados}

A primeira questão levantada aos estudantes foi sobre o interesse despertado pela ferramenta Google Classroom em sala de aula. Sendo assim, todos os estudantes afirmaram que a ferramenta é interessante de ser utilizada.

\section{2 respostas}

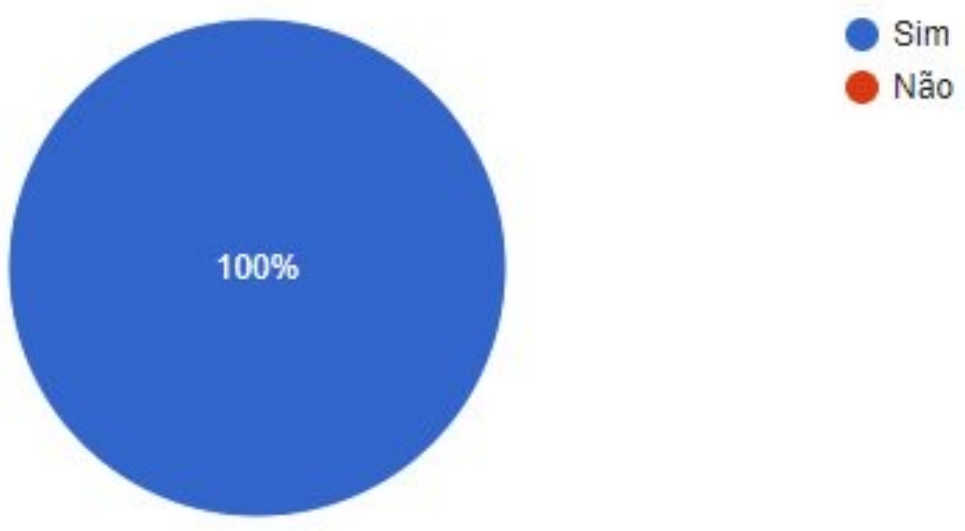

Figura 1 - Interesse da utilização do Google Classroom. Fonte: dados da pesquisa dos autores

A segunda questão levantada aos estudantes foi sobre qual ferramenta educacional eles preferiam utilizar, o portal educacional FAPAM ou a ferramenta Google Classroom. Sendo assim, onze estudantes afirmam preferir utilizar a ferramenta Google Classroom. 


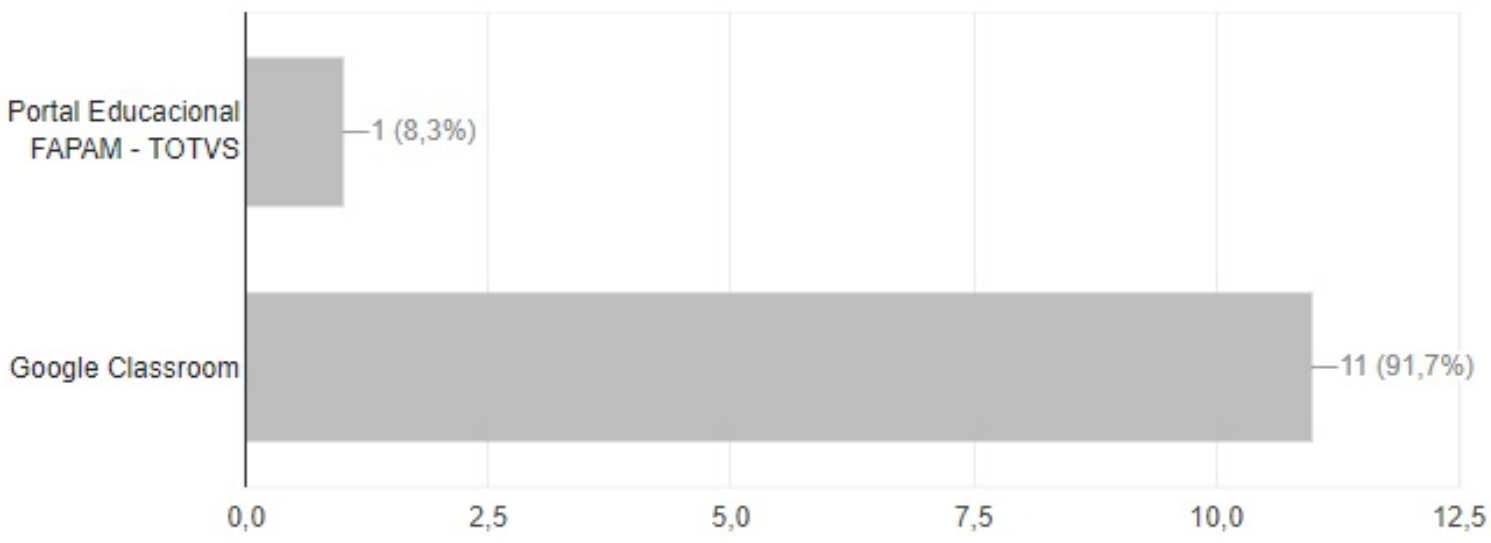

Figura 2 - Preferência de ferramenta. Fonte: dados da pesquisa dos autores

A terceira questão levantada aos estudantes foi sobre quais requisitos eles julgam para uma boa ferramenta para uso em sala de aula. $41,7 \%$ dos estudantes afirmam que uma boa ferramenta deve ser de fácil utilização. 33,3\% consideram que uma boa ferramenta deve ser de fácil envio de atividades. 66,7\% consideram que uma boa ferramenta deve ser ágil. 50\% dos estudantes afirmam que uma boa ferramenta deve possuir algum canal de comunicação com 0 aluno quando alguma atividade for disponibilizada/alterada. Nenhum aluno considerou que uma boa ferramenta deve ser colorida.

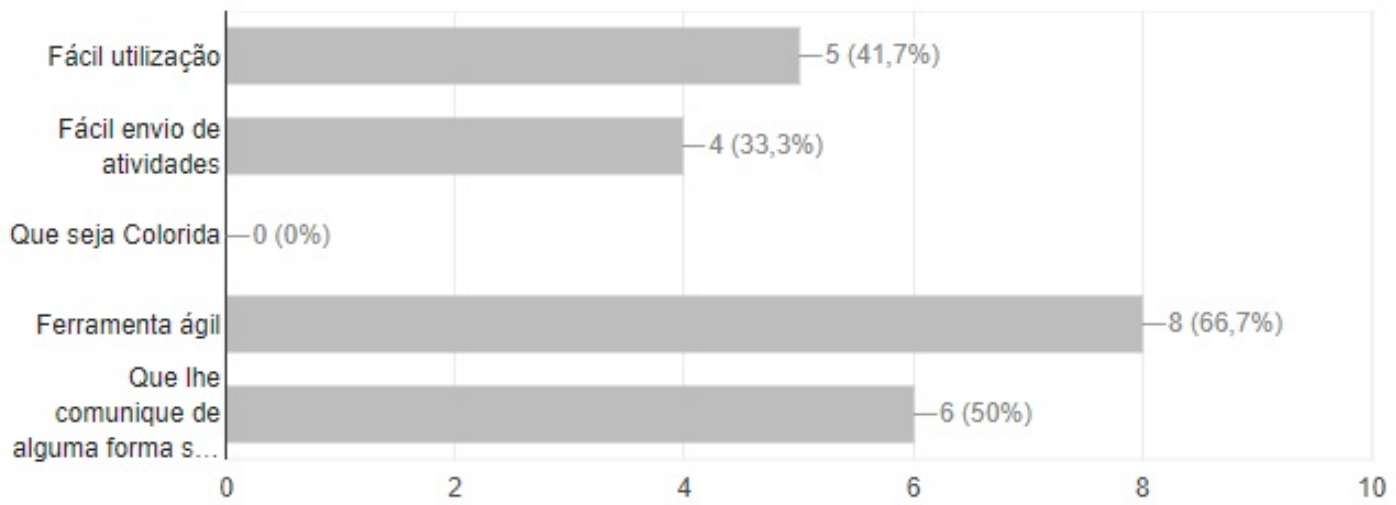

Figura 3 - Requisitos para uma boa ferramenta. Fonte: dados da pesquisa dos autores

Por último foi perguntado se o estudante recomendaria a ferramenta Google Clasroom a algum professor ou escola que solicitasse ajuda de uma ferramenta escolar. Sendo assim, todos os estudantes recomendaram a ferramenta como auxílio educacional.

\section{Conclusões}


A partir dos dados e resultados analisados, concluímos que a ferramenta Google Classroom apesar de relativamente nova, possui um grande potencial como aliada no processo de ensino e aprendizagem. A ferramenta que dispõe de muitos recursos úteis, são percebidos pelos alunos como uma ferramenta a ser recomendada e de fácil utilização. Ressalta-se que quando confrontado com ferramentas acadêmicas consolidadas, o software Google Classroom se apresenta na preferência dos estudantes pela agilidade e facilidade em sua utilização.

Ressalta-se que para o bom desempenho da ferramenta, o docente deve engajar-se no aprendizado da ferramenta, que possui muitas possibilidades. Uma sugestão aos ambientes educacionais que desejarem fazer uso da ferramenta, é criar um pequeno curso de formação docente, de poucas horas, de forma a orientar e tirar dúvidas que possam surgir. Bem como a apresentação da ferramenta aos alunos e caso possível a experimentação em laboratórios ou smartphones. A tecnologia já faz parte do cotidiano dos estudantes, aproximar a sala da realidade cotidiana do aluno é um passo importante no processo de ensino e aprendizagem.

\section{Referências}

ARAÚJO, H. M. C. O uso das ferramentas do aplicativo "Google sala de aula" no ensino de matemática. Catalão-GO, 2016, 93 p.

FINARDI, K. R. PIMENTEL, B. Crenças de professores de inglês sobre o uso do Facebook. Revista (Con) textos Linguísticos, v. 7, n. 8.1, p. 238-253, 2013.

GIL, Antônio Carlos. Métodos e Técnicas de Pesquisa Social. 6. ed. São Paulo: Atlas, 2008, $216 p$.

KENSKI, V. M. Tecnologias e ensino presencial e a distância. Campinas-SP: 2 ed, Papirus, 2006.

MARCONI, Maria de Andrade; LAKATOS, Eva Maria. Fundamentos de Metodologia Cientifica. 7. ed. São Paulo: Atlas, 2010, 249 p.

PRANDINI, R. C. Formação do formador para a atuação docente mediatizada pelas tecnologias da informação e comunicação. In: HESSEL, A.; PESCE, L.; ALEGRETTI, S. Formação online de educadores: identidade em construção. São Paulo: RG Editores, 2009 , p. $63-88$. 
PRESSMAN, R. S. Engenharia de Software. AMGH Editora, 2009.

VALENTE, José Armando. O computador e o conhecimento - repensando a educação. São Paulo: Gráfica UNICAMP, 1993. 